\title{
DETERMINANTES DA DISPERSÃO DA RENDA NO MEIO RURAL BRASILEIRO
}

\author{
Geraldo da Silva e Souza \\ Empresa Brasileira de Pesquisa Agropecuária (Embrapa) \\ geraldo.souza@embrapa.br \\ Eliane Gonçalves Gomes \\ Empresa Brasileira de Pesquisa Agropecuária (Embrapa) \\ eliane.gomes@embrapa.br \\ Eliseu Roberto de Andrade Alves \\ Empresa Brasileira de Pesquisa Agropecuária (Embrapa) \\ eliseu.alves@embrapa.br
}

\begin{abstract}
Resumo
Este artigo tem por objetivo a especificação de modelos econométricos explicativos da dispersão da renda rural no Brasil. Utilizam-se como covariáveis tecnologia e variáveis ambientais, sociais e demográficas pertinentes ao entorno rural. A abordagem é regional e com modelagem via regressão fracionária e método de momentos generalizado - GMM. A variável tecnológica cristaliza o processo de produção. É uma medida de eficiência técnica do tipo DEA (Análise de Envoltória de Dados) calculada no nível municipal e tem por base o Censo Agropecuário brasileiro de 2006. As condições de entorno variam em poder explicativo por região. A variável tecnologia também apresenta intensidades regionais distintas e é dominante na relação econométrica da dispersão da renda.
\end{abstract}

Palavras-Chaves: Concentração de renda; Agricultura; Regressão; GMM.

\begin{abstract}
In this article we fit an econometric model to explain rural income dispersion in Brazil. The covariates are technology and environmental, social and demographic indices related to the surroundings' conditions. The analysis is performed on a regional basis and the statistical approach uses fractional regression and generalized method of moments - GMM. The technological variable crystallizes the production process. It is a Data Envelopment Analysis (DEA) measure of technical efficiency on a county basis. The production process uses data collected from the Brazilian Agricultural Census of 2006. The surroundings' conditions vary in regional intensity. Technology is significant and dominates the relationship in all regions.
\end{abstract}

Keywords: $\quad$ Income concentration; Agriculture; Regression; GMM.

\section{INTRODUÇÃO}

Em estudo recente com base nos microdados do Censo Agropecuário brasileiro de 2006, Alves et al. (2013) sugerem forte dispersão da renda no meio rural brasileiro. De fato, como bem acentuam os autores, 500.000 produtores rurais são responsáveis por $87 \%$ do valor da produção registrada no censo de 2006. Esses representam apenas $11 \%$ do total dos estabelecimentos recenseados. Embora tal dispersão seja observada em outros países, por exemplo, esse percentual é de $14 \%$ no caso europeu para o censo de 2010 e de $11 \%$ para os Estados Unidos segundo o censo de 2007, tem-se interesse na identificação dos fatores responsáveis pela dispersão da renda no meio rural no caso brasileiro. Há indicações de que esta seja resultante, principalmente, do uso de tecnologia. Outros fatores de importância são as imperfeições de mercado, que criam 
dificuldades para difusão e adoção de tecnologias no meio rural. Veja Alves e Souza (2015) para maiores detalhes. Alves e Souza (2015) também acentuam que, devido às imperfeições de mercado, pequenos produtores vendem sua produção por preços inferiores aos dos grandes produtores e compram insumos a preços superiores. Tais imperfeições são ditadas pelas condições de desenvolvimento da região na qual os estabelecimentos se inserem. Exemplos típicos de imperfeições de mercado são gerados pelos segmentos dos mercados financeiro, insumos, produtos e exportações, de infraestrutura de saneamento e eletricidade, de acesso à assistência técnica e à informação, educação.

Vê-se no caso brasileiro que a inclusão deste grupo volumoso de produtores excluídos no processo de produção agrícola pode incrementar substancialmente a produção agropecuária tornando os níveis de produtividade do país ainda mais competitivos no mercado internacional. Nossa abordagem para o problema contribui para a literatura afim, caracterizando explicitamente, via modelos econométricos, o tipo de dependência entre dispersão de renda e variáveis características de tecnologia e de condições de entorno, sugerindo regionalmente, que componentes são mais influentes. Tais resultados servem ao propósito de orientar ações de assistência técnica rural e de políticas públicas. Citam-se como exemplos de outros estudos que tratam dos determinantes da dispersão de renda no meio rural brasileiro os trabalhos de Neder e Silva (2004), Ferreira e Souza (2007), Ney e Hoffmann (2008, 2009), Helfand et al. (2009).

A variável dependente utilizada na análise aqui conduzida é o índice de variabilidade de Gini, calculado para cada município com base nas rendas brutas rurais de seus estabelecimentos. Assim, o índice de Gini é uma medida de dispersão da renda bruta. A variável tecnologia é definida pelo escore de desempenho municipal, medido por meio de um modelo DEA (Data Envelopment Analysis) com retornos variáveis à escala e orientação a produto. O modelo de produção assumido toma como variável de produto a renda bruta da atividade rural e como insumos as despesas com terra, capital e trabalho. Como variáveis de entorno consideram-se indicadores referentes a características sociais, ambientais e demográficas. A possibilidade de endogeneidade da tecnologia é tratada via o método de momentos generalizado.

Nossa discussão procede com segue. Na Seção 2 descrevem-se o modelo de produção no nível municipal, as variáveis de insumo e produto e suas transformações. Apresentam-se também as variáveis contextuais de interesse que potencialmente podem afetar a dispersão da renda bruta rural. Na Seção 3 apresenta-se a classe de modelos econométricos utilizada nas avaliações de efeitos estatísticos. As técnicas consideradas combinam regressão fracionária com métodos de variáveis instrumentais. Na Seção 4 apresentam-se os resultados estatísticos e as análises derivadas. Finalmente, na Seção 5 apresentam-se um resumo dos resultados obtidos e as conclusões do estudo, especialmente no que se refere a implicações para políticas públicas.

\section{VARIÁVEIS DE PRODUÇÃO E CONTEXTUAIS}

Os dados de produção utilizados neste trabalho foram obtidos dos microdados do Censo Agropecuário de 2006. Foram agregados em nível municipal. Considerou-se a renda bruta rural média do estabelecimento como variável resposta do modelo de produção e os gastos médios com terra, trabalho e insumos tecnológicos, por município, como fatores de produção. Essas variáveis foram transformadas para ordenações (ranks). Essa abordagem empresta propriedades estatísticas não paramétricas à análise e contorna problemas associados à presença de atipicidades (outliers) e à escala de operação. A Tabela 1 descreve em detalhes essas variáveis. Têm-se dados válidos para 4.961 municípios, que representam $89,2 \%$ do total de municípios brasileiros. 
Tabela 1: Descrição das Variáveis de produção.

\begin{tabular}{|l|l|l|l|}
\hline Variável & Componentes & Unidade & Comentário \\
\hline Y (produção) & Renda bruta do estabelecimento & Reais & $\begin{array}{l}\text { Valor total da produção } \\
\text { agropecuária do } \\
\text { estabelecimento }\end{array}$ \\
\hline Terra & $4 \%$ do valor da terra & Reais & Valor de aluguel da terra \\
\hline Trabalho & $\begin{array}{l}\text { Salários ou outras formas de } \\
\text { compensação pagos à família e } \\
\text { aos trabalhadores contratados }\end{array}$ & Reais & - \\
\hline $\begin{array}{l}\text { Capital } \\
\text { insumos } \\
\text { tecnológicos) }\end{array}$ & $\begin{array}{l}\text { Maquinário, melhorias no } \\
\text { estabelecimento, aluguéis de } \\
\text { equipamentos, valor de culturas } \\
\text { permanentes, valor dos animais, } \\
\text { valor das matas plantadas, valor } \\
\text { de sementes, valor de sal e } \\
\text { forragens, valor de medicamentos, } \\
\text { adubação e pesticidas, despesas } \\
\text { com combustíveis, eletricidade, } \\
\text { armazenagem, matérias primas e } \\
\text { outros gastos }\end{array}$ & Reais & $\begin{array}{l}\text { Todos os valores de } \\
\text { estoques foram depreciados } \\
\text { à taxa de 6\% ao ano num } \\
\text { período determinado que } \\
\text { varia com o tipo do estoque } \\
\text { (máquinas - 15 anos; matas } \\
\text { plantadas - 20 anos; } \\
\text { culturas permanentes - 15 } \\
\text { anos; benfeitorias - 50 } \\
\text { anos; animais - 5 anos) }\end{array}$ \\
\hline
\end{tabular}

As variáveis contextuais consideradas no estudo são descritas a seguir e foram sugeridas por nota técnica não publicada do Instituto CNA (Confederação Nacional da Agricultura, 2013). São componentes das dimensões social, demográfica e ambiental do desenvolvimento rural. Foram transformadas em ranks e normalizadas pelo máximo.

a) Índice de desempenho do SUS. Este indicador afere o desempenho do Sistema Único de Saúde (SUS), levando em conta as dimensões de acesso aos serviços, de efetividade da atenção básica, ambulatorial, hospitalar e emergencial no município. Essa variável reflete tanto o acesso a bens públicos (saúde) quanto a melhor expectativa de vida da população do município (Ministério da Saúde, 2011).

b) Existência de energia elétrica. Proporção de domicílios rurais dotados de energia elétrica no município (IBGE, 2012b).

c) Índice de desenvolvimento da educação básica. É um indicador que avalia o desempenho dos estudantes em exames padronizados, combinado com informações sobre o rendimento escolar. No caso dessa variável foram consideradas as notas médias obtidas por alunos da rede pública tanto rural como urbana do município em 2009. Esse índice reflete a qualidade educacional da população (INEP, 2012).

d) Taxa de envelhecimento. Refere-se ao inverso da razão entre a população acima de 60 anos e a população total do município (IBGE, 2012b).

e) Proporção de domicílios com destino adequado do lixo. Complementar da proporção de domicílios em que o lixo foi jogado em terreno baldio ou logradouro, ou jogado em rio, lago ou mar (IBGE, 2012a).

f) Abastecimento de água. Considerado associado positivamente com o desenvolvimento rural quando se dá através de poço ou nascente localizado no próprio domicílio ou quando ligado à rede geral de abastecimento de água. É medido pela proporção de domicílios no município com uma dessas duas formas de abastecimento (IBGE, 2012b).

$\mathrm{Na}$ análise das regiões Sudeste e Centro-Oeste foi necessário utilizar indicadores agregados das dimensões social, demográfica e ambiental. As variáveis componentes desses indicadores foram combinadas por técnica multivariada como 
sugerida por Moreira et al. (2004). O indicador, na realidade, é uma média ponderada das variáveis transformadas com a ponderação da $i$-ésima componente igual a $R_{i}^{2} / \sum_{j} R_{j}^{2}$, sendo $R_{i}^{2}$ o coeficiente de correlação múltipla obtido da regressão da $i$ ésima variável nas demais. Um conjunto similar de variáveis foi considerado pelo Instituto CNA (Confederação Nacional da Agricultura, 2013) visando à construção de um indicador global de desenvolvimento rural.

\section{ABORDAGEM METODOLÓGICA}

Nosso interesse neste estudo é explicar o efeito de variáveis tecnológicas e de desenvolvimento na dispersão da renda rural. Como medida de dispersão - variável dependente, toma-se o índice de dispersão de Gini municipal. Se $x_{i}$ é o valor de uma observação de uma variável não negativa e não identicamente nula, o índice de dispersão de Gini é definido por $g / 2 \bar{x}$, onde $g=\left(1 / n^{2}\right) \sum_{i=1}^{n} \sum_{j=1}^{n}\left|x_{i}-x_{j}\right|$ e $\bar{x}$ é a média amostral das observações $x_{i}$. O índice de Gini varia no intervalo [0,1), com valores próximos a um indicando concentrações mais intensas.

\subsection{Modelo de Produção}

Considere-se um processo de produção composto por 4.961 firmas (municípios). Cada município faz uso do vetor de insumos $\left(x_{1}, x_{2}, x_{3}\right)-$ terra, trabalho e capital (ver Tabela 1) - para produzir o nível de produto $y$. Seja $Y=\left(y_{1}, y_{2}, \ldots, y_{5474}\right)$ o vetor produto do processo. Seja $X$ a matriz $3 \times 4.961$ de uso dos insumos. A $r$-ésima coluna de $X$ é o vetor de insumos utilizados pelo município $r$.

A medida de eficiência técnica de produção $\phi^{*}\left(x_{o}, y_{o}\right)$, mais geralmente de desempenho, para o município $o$, com vetor de produção $\left(x_{o}, y_{o}\right)$, derivada da abordagem de DEA, orientada a produto e com retornos variáveis à escala (Banker et al., 1984), é dada por:

$$
\phi^{*}\left(x_{o}, y_{o}\right)=\max _{\phi, \lambda} \phi
$$

sujeito a

i) $Y \lambda \geq \phi y_{o}$, ii) $X \lambda \leq x_{o}$ e iii) $\lambda \geq 0, \lambda 1=1, \phi$ livre

Faz-se mister observar aqui que as variáveis de produção (produto e insumos) foram consideradas como médias por município, transformadas a ranks e normalizadas pelo máximo no cálculo da medida DEA de performance. A transformação em ranks é compatível com as transformações utilizadas nas variáveis contextuais e define uma abordagem não paramétrica que permite a estimativa da eficiência sem a influência de valores extremos no espaço das variáveis de produção. É também uma transformação usual em Estatística Não Paramétrica na presença de não normalidade, observações atípicas e heteroscedasticidade (Connover, 1999). O uso do DEA neste estudo considera a medida de eficiência técnica como cristalizadora do efeito tecnológico na explicação da dispersão da renda. Portanto, aparece como variável independente na especificação da função resposta definida pela dispersão. Maiores detalhes sobre os modelos DEA podem ser vistos, por exemplo, em Cooper et al. (2011).

\subsection{ANÁlise ESTatística da InfluênCIa das Covariáveis na MEdida de DisPersão}

O modelo estatístico utilizado baseia-se em regressão com variável dependente limitada e é similar à proposta de Papke e Wooldridge (1996) e Ramalho et al. (2010) de regressão fracionária, combinada com os resultados de método de momentos generalizados - GMM (Gallant, 1987; Davidson e MacKinnon, 1993; Greene, 2011), conforme proposto em Souza e Gomes (2015). 
Seja $\hat{\theta}_{\tau}$ a dispersão da renda no município $\tau$ e $w_{\tau}$ o vetor de variáveis contextuais. Postula-se que $\hat{\theta}_{\tau}=G\left(w_{\tau} \delta\right)+\varepsilon_{\tau}$, sendo $G($.) uma função de distribuição de probabilidades. O parâmetro desconhecido $\delta$ é estimado por GMM. Nesta formulação permite-se que a variável tecnologia seja potencialmente endógena. Como vetor de instrumentos $z_{\tau}$ utilizam-se nesta análise todos os indicadores de desenvolvimento do entorno dos estabelecimentos rurais. A condição de momentos vem dada por $E\left(z_{\tau} \otimes\left[\theta_{\tau}-G\left(w_{\tau} \delta\right)\right]\right)=0$, onde $\otimes$ denota produto direto. Escolhas competitivas para $G$ são as funções de distribuição logística, normal padrão e a inversa da distribuição do valor extremo. São dadas, respectivamente, por $G(u)=e^{u} /\left(1+e^{u}\right), G(u)=\Phi(u)$, e $G(u)=1-e^{-e^{u}}$. A função $\Phi(u)$ é a normal padrão.

A análise foi levada a efeito regionalmente, visto que não se obtém representatividade adequada em um modelo global.

O índice de Gini e o de tecnologia captam as mesmas imperfeições de mercado e, portanto, espera-se associação forte no mesmo sentido entre essas medidas. A hipótese básica é de que altos valores da medida de eficiência técnica são indicativos de informação e acesso a tecnologia, que só estariam disponíveis aos estabelecimentos rurais com maiores níveis de renda ${ }^{1}$. Isso se deve às imperfeições de mercado.

\section{RESULTADOS ESTATÍSTICOS E IMPLICAÇÕES}

A Tabela 2 apresenta médias das variáveis explicativas para as regiões brasileiras. As condições de entorno variam regionalmente. De um modo geral, as regiões Norte e Nordeste apresentam indicadores menos favoráveis em todos os construtos avaliados. O mesmo resultado é obtido combinando-se os atributos nas dimensões ambiental, social e demográfica. Pela média, a variável tecnologia é dominada pela região Centro-Oeste, seguida das regiões Sudeste e Sul. Aqui também o pior desempenho recai sobre as regiões Norte e Nordeste.

A dispersão de renda (índice de Gini) por região é apresentada na Tabela 3. O nível de dispersão, pela média, difere significativamente entre as regiões e é substancialmente menor na região Sul. A análise detalhada da dispersão em função das covariáveis de interesse é avaliada separadamente via os modelos estatísticos aplicados regionalmente. Os resultados dos modelos regionais são descritos a seguir.

\subsection{EFEITOS ESPERAdos das CovariáveIS NO ÍNDICE DE GINI}

As covariáveis agem de forma inversa às imperfeições de mercado. Pequenos valores destes indicadores deverão implicar em ganhos de eficiência técnica para estabelecimentos rurais de alta renda e concentração de renda longe de zero. Neste contexto, esperam-se contribuições negativas no modelo para as variáveis indicadoras de mercado e uma contribuição positiva para a tecnologia. De fato, esse padrão foi observado na região Sul. Para as demais regiões observou-se uma violação desta condição para alguns atributos, outros que tecnologia, devido aos diferentes níveis de desenvolvimento experimentado por cada região.

\footnotetext{
${ }^{1}$ A área do estabelecimento tem pequena influência na renda, e domina a da tecnologia (Alves et al., 2013).
} 
Tabela 2: Variáveis explicativas por região.

\begin{tabular}{|c|c|c|c|c|c|}
\hline \multirow{6}{*}{$\begin{array}{l}\text { Variável } \\
\text { Domicílios com } \\
\text { destino adequado } \\
\text { do lixo }\end{array}$} & \multirow{2}{*}{$\begin{array}{l}\text { Região } \\
\text { Norte }\end{array}$} & \multirow{2}{*}{$\begin{array}{r}\text { Média } \\
0,4282\end{array}$} & \multirow{2}{*}{$\begin{array}{r}\text { Desvio padrão } \\
0,0099\end{array}$} & \multicolumn{2}{|c|}{$95 \%$ intervalo de confiança } \\
\hline & & & & 0,4088 & 0,4477 \\
\hline & Nordeste & 0,2211 & 0,0041 & 0,2130 & 0,2292 \\
\hline & Sudeste & 0,6520 & 0,0063 & 0,6397 & 0,6643 \\
\hline & Sul & 0,7780 & 0,0050 & 0,7682 & 0,7878 \\
\hline & Centro-Oeste & 0,5977 & 0,0135 & 0,5713 & 0,6241 \\
\hline \multirow{5}{*}{$\begin{array}{l}\text { Taxa de } \\
\text { Envelhecimento }\end{array}$} & Norte & 0,8183 & 0,0097 & 0,7993 & 0,8373 \\
\hline & Nordeste & 0,6252 & 0,0053 & 0,6148 & 0,6357 \\
\hline & Sudeste & 0,3931 & 0,0063 & 0,3808 & 0,4054 \\
\hline & Sul & 0,2862 & 0,0071 & 0,2724 & 0,3001 \\
\hline & Centro-Oeste & 0,6900 & 0,0168 & 0,6570 & 0,7229 \\
\hline \multirow{5}{*}{$\begin{array}{l}\text { Existência de } \\
\text { energia elétrica }\end{array}$} & Norte & 0,1336 & 0,0063 & 0,1212 & 0,1459 \\
\hline & Nordeste & 0,3525 & 0,0052 & 0,3423 & 0,3627 \\
\hline & Sudeste & 0,6694 & 0,0068 & 0,6560 & 0,6828 \\
\hline & Sul & 0,7422 & 0,0062 & 0,7301 & 0,7543 \\
\hline & Centro-Oeste & 0,3566 & 0,0155 & 0,3262 & 0,3870 \\
\hline \multirow{5}{*}{$\begin{array}{l}\text { Índice de } \\
\text { desenvolvimento } \\
\text { da educação } \\
\text { básica }\end{array}$} & Norte & 0,3273 & 0,0080 & 0,3117 & 0,3429 \\
\hline & Nordeste & 0,2187 & 0,0037 & 0,2114 & 0,2260 \\
\hline & Sudeste & 0,7479 & 0,0048 & 0,7385 & 0,7574 \\
\hline & Sul & 0,6585 & 0,0060 & 0,6467 & 0,6702 \\
\hline & Centro-Oeste & 0,5375 & 0,0116 & 0,5147 & 0,5603 \\
\hline \multirow{5}{*}{$\begin{array}{l}\text { Abastecimento de } \\
\text { água no domicílio } \\
\text { rural }\end{array}$} & Norte & 0,4949 & 0,0153 & 0,4650 & 0,5248 \\
\hline & Nordeste & 0,2879 & 0,0055 & 0,2771 & 0,2987 \\
\hline & Sudeste & 0,5885 & 0,0068 & 0,5752 & 0,6017 \\
\hline & Sul & 0,6465 & 0,0067 & 0,6333 & 0,6596 \\
\hline & Centro-Oeste & 0,6307 & 0,0147 & 0,6019 & 0,6594 \\
\hline \multirow{5}{*}{$\begin{array}{l}\text { Índice de } \\
\text { desempenho do } \\
\text { SUS }\end{array}$} & Norte & 0,2243 & 0,0121 & 0,2006 & 0,2479 \\
\hline & Nordeste & 0,3449 & 0,0050 & 0,3351 & 0,3547 \\
\hline & Sudeste & 0,6269 & 0,0065 & 0,6140 & 0,6397 \\
\hline & Sul & 0,7326 & 0,0066 & 0,7197 & 0,7454 \\
\hline & Centro-Oeste & 0,3308 & 0,0127 & 0,3058 & 0,3557 \\
\hline \multirow{5}{*}{$\begin{array}{l}\text { Tecnologia } \\
\text { (escore DEA de } \\
\text { performance) }\end{array}$} & Norte & 0,4545 & 0,0106 & 0,4338 & 0,4753 \\
\hline & Nordeste & 0,2864 & 0,0058 & 0,2750 & 0,2978 \\
\hline & Sudeste & 0,6398 & 0,0067 & 0,6266 & 0,6530 \\
\hline & Sul & 0,6356 & 0,0053 & 0,6251 & 0,6461 \\
\hline & Centro-Oeste & 0,7719 & 0,0135 & 0,7454 & 0,7983 \\
\hline \multirow{5}{*}{$\begin{array}{l}\text { Dimensão } \\
\text { ambiental } \\
\text { (indicador } \\
\text { agregado) }\end{array}$} & Norte & 0,4785 & 0,0035 & 0,4717 & 0,4852 \\
\hline & Nordeste & 0,4356 & 0,0020 & 0,4317 & 0,4394 \\
\hline & Sudeste & 0,5433 & 0,0018 & 0,5398 & 0,5468 \\
\hline & Sul & 0,5975 & 0,0017 & 0,5942 & 0,6008 \\
\hline & Centro-Oeste & 0,5513 & 0,0045 & 0,5424 & 0,5601 \\
\hline \multirow{5}{*}{$\begin{array}{l}\text { Dimensão social } \\
\text { (indicador } \\
\text { agregado) }\end{array}$} & Norte & 0,3233 & 0,0070 & 0,3096 & 0,3370 \\
\hline & Nordeste & 0,2436 & 0,0024 & 0,2389 & 0,2483 \\
\hline & Sudeste & 0,6702 & 0,0044 & 0,6616 & 0,6788 \\
\hline & Sul & 0,7291 & 0,0037 & 0,7218 & 0,7364 \\
\hline & Centro-Oeste & 0,5579 & 0,0083 & 0,5416 & 0,5742 \\
\hline
\end{tabular}


Tabela 2: Continuação

\begin{tabular}{llrrrr}
\hline Variável & Região & Média & Desvio padrão & 95\% intervalo de confiança \\
\hline \multirow{2}{*}{ Dimensão } & Norte & 0,4638 & 0,0053 & 0,4535 & 0,4741 \\
demográfica & Nordeste & 0,4003 & 0,0021 & 0,3961 & 0,4045 \\
(indicador & Sudeste & 0,5587 & 0,0031 & 0,5527 & 0,5648 \\
agregado) & Sul & 0,5287 & 0,0031 & 0,5226 & 0,5349 \\
& Centro-Oeste & 0,6373 & 0,0092 & 0,6193 & 0,6554 \\
\hline
\end{tabular}

Tabela 3: Índice de Gini por região (dispersão da renda rural).

\begin{tabular}{lrrrr}
\hline Região & Média & Desvio padrão & $95 \%$ intervalo de confiança \\
\hline Norte & 0,7850 & 0,0046 & 0,7760 & 0,7941 \\
Nordeste & 0,7991 & 0,0024 & 0,7944 & 0,8037 \\
Sudeste & 0,8078 & 0,0023 & 0,8034 & 0,8122 \\
Sul & 0,7541 & 0,0030 & 0,7483 & 0,7599 \\
Centro-Oeste & 0,8390 & 0,0048 & 0,8295 & 0,8484 \\
\hline
\end{tabular}

\subsection{REGIÃo NORTE}

A Tabela 4 mostra os resultados obtidos com a utilização do software Stata 13.1 (Stata, 2013). O teste de especificação de Hansen (StataCorp, 2012) valida o modelo e o conjunto de instrumentos utilizados (2,7353 com 2 graus de liberdade; $\mathrm{p}$ valor $=0,2547)$.

Tabela 4: Resultados do modelo para a região Norte.

\begin{tabular}{|c|c|c|c|c|c|c|}
\hline Variáveis & Coeficiente & $\begin{array}{l}\text { Desvio } \\
\text { padrão }\end{array}$ & $\mathrm{Z}$ & $\mathrm{P}>|\mathrm{z}|$ & \multicolumn{2}{|c|}{$\begin{array}{r}95 \% \text { intervalo de } \\
\text { confiança } \\
\end{array}$} \\
\hline Constante & 0,4576 & 0,1286 & 3,5600 & 0,0000 & 0,2056 & 0,7096 \\
\hline $\begin{array}{l}\text { Proporção de domicílios } \\
\text { com destino do lixo } \\
\text { adequado }\end{array}$ & $-0,0299$ & 0,0850 & $-0,3500$ & 0,7250 & $-0,1965$ & 0,1367 \\
\hline Taxa de envelhecimento & 0,0159 & 0,0978 & 0,1600 & 0,8710 & $-0,1758$ & 0,2075 \\
\hline $\begin{array}{l}\text { Existência de energia } \\
\text { elétrica total rural }\end{array}$ & $-0,2951$ & 0,1595 & $-1,8500$ & 0,0640 & $-0,6077$ & 0,0174 \\
\hline $\begin{array}{l}\text { Índice de desenvolvimento } \\
\text { da educação básica }\end{array}$ & $-0,2867$ & 0,1077 & $-2,6600$ & 0,0080 & $-0,4977$ & 0,0757 \\
\hline $\begin{array}{l}\text { Tipo de abastecimento de } \\
\text { água no domicilio rural }\end{array}$ & 0,0722 & 0,0585 & 1,2300 & 0,2180 & $-0,0426$ & 0,1869 \\
\hline $\begin{array}{l}\text { Índice de desempenho do } \\
\text { SUS }\end{array}$ & 0,2565 & 0,0732 & 3,5100 & 0,0000 & 0,1131 & 0,3999 \\
\hline Tecnologia (escore DEA) & 0,8527 & 0,2383 & 3,5800 & 0,0000 & 0,3856 & 1,3197 \\
\hline
\end{tabular}

A variável resposta (dispersão da renda) é explicada na região Norte pelos atributos proporção de domicílios com destino do lixo adequado, taxa de envelhecimento, existência de energia elétrica total rural, índice de desenvolvimento da educação básica, tipo de abastecimento de água no domicilio rural, índice de desempenho do SUS e tecnologia (medida DEA de desempenho de produção). Esta última é considerada endógena. Como instrumentos tomou-se a razão entre a população rural e urbana do município, a proporção de estabelecimentos que praticam a queimada, a média de moradores por domicílio rural, a proporção de domicílios com destino do lixo adequado, a taxa de envelhecimento, a existência de energia elétrica total rural, o índice de desenvolvimento da educação básica, o tipo de abastecimento de água no domicilio rural e o índice de desempenho do SUS.

Obteve-se significância estatística para existência de energia elétrica total rural, para o índice de desenvolvimento da educação básica, índice de desempenho do SUS e 
tecnologia. Somente o índice de desempenho do SUS teve sinal oposto ao esperado, fazendo o seu incremento aumentar a dispersão da renda bruta. Ou seja, o indicador ainda não foi capaz de atenuar as imperfeições de mercado em nível rural, como reflexo do baixo desempenho do SUS na região - rank médio de 0,2243, o menor do país. A relação é dominada pela tecnologia, indicando forte associação positiva com o índice de Gini.

\subsection{REgIÃo NORDESTE}

A Tabela 5 traz os resultados obtidos para a região Nordeste. O teste de especificação de Hansen valida o modelo e o conjunto de instrumentos utilizados $(4,9930$ com 3 graus de liberdade; $p$-valor $=0,1723)$.

Tabela 5: Resultados do modelo para a região Nordeste.

\begin{tabular}{|c|c|c|c|c|c|c|}
\hline Variáveis & Coeficiente & $\begin{array}{l}\text { Desvio } \\
\text { padrão }\end{array}$ & $\mathrm{Z}$ & $\mathrm{P}>|\mathrm{z}|$ & \multicolumn{2}{|c|}{$\begin{array}{r}95 \% \text { intervalo de } \\
\text { confiança } \\
\end{array}$} \\
\hline Constante & 0,3560 & 0,0330 & 10,79 & 0,0000 & 0,2913 & 0,4207 \\
\hline $\begin{array}{l}\text { Proporção de domicílios } \\
\text { com destino do lixo } \\
\text { adequado }\end{array}$ & 0,2825 & 0,0657 & 4,30 & 0,0000 & 0,1537 & 0,4113 \\
\hline Taxa de envelhecimento & 0,1697 & 0,0542 & 3,13 & 0,0020 & 0,0634 & 0,2760 \\
\hline $\begin{array}{l}\text { Existência de energia } \\
\text { elétrica total rural }\end{array}$ & 0,1540 & 0,0366 & 4,20 & 0,0000 & 0,0822 & 0,2258 \\
\hline $\begin{array}{l}\text { Índice de desenvolvimento } \\
\text { da educação básica }\end{array}$ & 0,0183 & 0,0485 & 0,38 & 0,7060 & $-0,0768$ & 0,1135 \\
\hline $\begin{array}{l}\text { Tipo de abastecimento de } \\
\text { água no domicilio rural }\end{array}$ & $-0,1026$ & 0,0351 & $-2,92$ & 0,0030 & $-0,1714$ & $-0,0337$ \\
\hline $\begin{array}{l}\text { Índice de desempenho do } \\
\text { SUS }\end{array}$ & 0,4351 & 0,0358 & 1,21 & 0,2250 & $-0,0268$ & 0,1138 \\
\hline Tecnologia (escore DEA) & 1,0597 & 0,1544 & 6,87 & 0,0000 & 0,7572 & 1,3622 \\
\hline
\end{tabular}

A dispersão da renda é explicada na região Nordeste pelos atributos proporção de domicílios com destino do lixo adequado, taxa de envelhecimento, existência de energia elétrica total rural, índice de desenvolvimento da educação básica, tipo de abastecimento de água no domicilio rural, índice de desempenho do SUS e tecnologia (endógena). Como instrumentos tomou-se a razão entre a população rural e urbana do município, a proporção de estabelecimentos que praticam a queimada, o índice de migração, a vulnerabilidade das crianças com até cinco anos de idade (condição educacional da família e saneamento do domicílio), a proporção de domicílios com destino do lixo adequado, a taxa de envelhecimento, a existência de energia elétrica total rural, o índice de desenvolvimento da educação básica, o tipo de abastecimento de água no domicilio rural e o índice de desempenho do SUS.

Obteve-se significância estatística para proporção de domicílios com destino do lixo adequado, taxa de envelhecimento, existência de energia elétrica total rural, tipo de abastecimento de água no domicílio rural e tecnologia. A relação é dominada pela tecnologia, indicando forte associação positiva com o índice de Gini. A variável que aparentemente pode reduzir a dispersão de renda é o tipo de abastecimento de água. É evidente a associação das condições de entorno com o nível de dispersão. A direção da associação é explicada pelas mesmas razões do comentário sobre o SUS na região Norte. A região Nordeste apresenta os menores valores do país para a proporção de domicílios com destino adequado do lixo e um dos piores para existência de energia elétrica. Ou seja, no meio rural do Nordeste, à exceção do tipo de abastecimento de água, os investimentos feitos não foram capazes de eliminar a influência das imperfeições de mercado, revertendo os sinais dos coeficientes para negativo. 


\subsection{REGIão SUDESTE}

A Tabela 6 apresenta os resultados obtidos para a região Sudeste. A estatística de Hansen com 4 graus de liberdade é 2,1745 e p-valor 0,7037.

Tabela 6: Resultados do modelo para a região Sudeste.

\begin{tabular}{lrrrrrr}
\hline Variáveis & Coeficiente & $\begin{array}{r}\text { Desvio } \\
\text { padrão }\end{array}$ & $\mathrm{z}$ & $\mathrm{P}>|\mathrm{z}|$ & $\begin{array}{r}95 \% \text { intervalo de } \\
\text { confiança }\end{array}$ \\
\hline Constante & 0,5818 & 0,0665 & 8,75 & 0,0000 & 0,4516 & 0,7121 \\
Demográfico & $-0,4555$ & 0,1228 & $-3,71$ & 0,0000 & $-0,6961$ & $-0,2148$ \\
Ambiental & 0,6132 & 0,1303 & 4,71 & 0,0000 & 0,3578 & 0,8686 \\
Social & $-0,7684$ & 0,1244 & $-6,18$ & 0,0000 & $-1,0122$ & $-0,5245$ \\
Tecnologia (escore DEA) & 1,1677 & 0,1410 & 8,28 & 0,0000 & 0,8913 & 1,4441 \\
\hline
\end{tabular}

Foi necessário usar os indicadores agregados das dimensões ambiental, demográfica e social. A componente ambiental agrega as variáveis proporção de estabelecimentos que utilizam agroquímicos, que praticam a queimada, que praticam rotação de culturas, que praticam plantio direto, que praticam plantio em curva de nível, que praticam cultivo mínimo, proporção de áreas de florestas e sistemas agroflorestais, proporção de áreas degradadas e proporções de domicílios com destino do lixo adequado. A dimensão demográfica contempla a média de moradores por domicílio rural, a taxa de envelhecimento, a razão de dependência isto é a razão entre a população considerada inativa ( 0 a 14 anos e 60 anos e mais de idade) sobre a população potencialmente ativa (15 a 59 anos de idade), razão entre população rural e urbana do município e o índice de migração. A dimensão social agrega a taxa de alfabetização, indicador de pobreza rural, rendimento médio mensal per capita nominal dos domicílios rurais, vulnerabilidade infantil, existência de energia elétrica, índice de desenvolvimento da educação básica, tipo de abastecimento de água no domicílio rural e índice de desempenho no SUS. Agregam-se, assim, variáveis ligadas às imperfeições de mercado. As variáveis tecnologia e ambiental foram consideradas endógenas.

Em princípio, as covariáveis, com exceção da tecnologia, deveriam ter sinal negativo de associação com o índice de Gini. Isto foi observado para as dimensões demográfica e social. O indicador ambiental apresentou sinal positivo, o que indicativo de concentração de renda. Este fato pode ser explicado pela observação de que o uso correto do ambiente pode expressar, em condições de imperfeição de mercado, alto uso de tecnologia e, assim, pode servir como concentrador de renda.

\subsection{REGIão SUL}

A Tabela 7 mostra os resultados obtidos para a região Sul. O teste de especificação de Hansen valida o modelo e o conjunto de instrumentos utilizados $(1,5043$ com 1 grau de liberdade; $p$-valor $=0,2200)$.

A variável resposta é explicada na região Sul pelos atributos proporção de domicílios com destino do lixo adequado, taxa de envelhecimento, existência de energia elétrica total rural, índice de desenvolvimento da educação básica, tipo de abastecimento de água no domicilio rural, índice de desempenho do SUS e tecnologia (medida DEA de desempenho de produção). Como instrumentos tomou-se a razão entre a população rural e urbana do município, a proporção de estabelecimentos que praticam a queimada, a proporção de domicílios com destino do lixo adequado, a taxa de envelhecimento, a existência de energia elétrica total rural, o índice de desenvolvimento da educação básica, o tipo de abastecimento de água no domicilio rural e o índice de desempenho do SUS.

No Sul, onde existe um ambiente em que as imperfeições de mercado são reduzidas e é forte o estímulo para reduzi-las ainda mais, os sinais dos coeficientes estão de acordo com esta visão, sendo negativos. Destoa a taxa de envelhecimento. 
Provavelmente, o efeito da idade poderia ser mais bem explicado pela idade do administrador do estabelecimento rural, já que este é o fator que pode afetar o processo de decisão no nível do estabelecimento. No entanto, a idade do produtor não está disponível no censo na forma de variável contínua. A proxy aqui escolhida para capturar esse efeito não funcionou apropriadamente em todas as regiões e pode estar refletindo as condições de saúde da população do município.

Tabela 7: Resultados do modelo para a região Sul.

\begin{tabular}{|c|c|c|c|c|c|c|}
\hline Variáveis & Coeficiente & $\begin{array}{l}\text { Desvio } \\
\text { padrão }\end{array}$ & $\mathrm{z}$ & $\mathrm{P}>|\mathrm{z}|$ & \multicolumn{2}{|c|}{$\begin{array}{r}95 \% \text { intervalo de } \\
\text { confiança }\end{array}$} \\
\hline Constante & 0,0040 & 0,1734 & 0,02 & 0,9820 & $-0,3359$ & 0,3438 \\
\hline $\begin{array}{l}\text { Proporção de domicílios } \\
\text { com destino do lixo } \\
\text { adequado }\end{array}$ & 0,0233 & 0,0812 & 0,29 & 0,7740 & $-0,1359$ & 0,1825 \\
\hline Taxa de envelhecimento & 0,1983 & 0,0635 & 3,12 & 0,0020 & 0,0738 & 0,3228 \\
\hline $\begin{array}{l}\text { Existência de energia } \\
\text { elétrica total rural }\end{array}$ & $-0,5464$ & 0,1097 & $-4,98$ & 0,0000 & $-0,7615$ & $-0,3313$ \\
\hline $\begin{array}{l}\text { Índice de desenvolvimento } \\
\text { da educação básica }\end{array}$ & $-0,2728$ & 0,0668 & $-4,09$ & 0,0000 & $-0,4036$ & $-0,1419$ \\
\hline $\begin{array}{l}\text { Tipo de abastecimento de } \\
\text { água no domicilio rural }\end{array}$ & $-0,2002$ & 0,0577 & $-3,47$ & 0,0010 & $-0,3134$ & $-0,0871$ \\
\hline $\begin{array}{l}\text { Índice de desempenho do } \\
\text { SUS }\end{array}$ & $-0,1610$ & 0,0636 & $-2,53$ & 0,0110 & $-0,2856$ & $-0,0363$ \\
\hline Tecnologia (escore DEA) & 2,3750 & 0,4001 & 5,94 & 0,0000 & 1,5909 & 3,1591 \\
\hline
\end{tabular}

\subsection{Região Centro-Oeste}

A Tabela 8 traz os resultados para a região Centro-Oeste. O teste de especificação de Hansen valida o modelo e o conjunto de instrumentos utilizados $(4,1436$ com 3 graus de liberdade; $p$-valor $=0,2464)$.

Tabela 8: Resultados do modelo para a região Centro-Oeste.

\begin{tabular}{lrrrrrr}
\hline Variáveis & Coeficiente & $\begin{array}{r}\text { Desvio } \\
\text { padrão }\end{array}$ & $\mathrm{z}$ & $\mathrm{P}>|\mathrm{z}|$ & $\begin{array}{r}95 \% \text { intervalo de } \\
\text { confiança }\end{array}$ \\
\hline Constante & 1,2654 & 0,2149 & 5,89 & 0,0000 & 0,8441 & 1,6867 \\
Ambiental & $-0,7453$ & 0,3577 & $-2,08$ & 0,0370 & $-1,4465$ & $-0,0442$ \\
Taxa de envelhecimento & $-0,0946$ & 0,1024 & $-0,92$ & 0,3560 & $-0,2953$ & 0,1061 \\
$\begin{array}{l}\text { Existência de energia } \\
\text { elétrica total rural }\end{array}$ & $-0,2032$ & 0,0954 & $-2,13$ & 0,0330 & $-0,3901$ & $-0,0162$ \\
$\begin{array}{l}\text { Indice de desenvolvimento } \\
\text { da educação básica }\end{array}$ & 0,0819 & 0,1225 & 0,67 & 0,5040 & $-0,1581$ & 0,3219 \\
$\begin{array}{l}\text { Tipo de abastecimento de } \\
\text { água no domicilio rural }\end{array}$ & $-0,1696$ & 0,0824 & $-2,06$ & 0,0400 & $-0,3311$ & $-0,0081$ \\
$\begin{array}{l}\text { Indice de desempenho do } \\
\text { SUS }\end{array}$ & $-0,0061$ & 0,1002 & $-0,06$ & 0,9510 & $-0,2025$ & 0,1903 \\
Tecnologia (escore DEA) & 0,4461 & 0,2210 & 2,02 & 0,0430 & 0,0130 & 0,8792 \\
\hline
\end{tabular}

A dispersão da renda é explicada na região Centro-Oeste pelo indicador agregado ambiental, pelos atributos taxa de envelhecimento, existência de energia elétrica total rural, índice de desenvolvimento da educação básica, tipo de abastecimento de água no domicilio rural, índice de desempenho do SUS e tecnologia (medida DEA de desempenho de produção). Como instrumentos tomou-se a razão entre a população rural e urbana do município, a média de moradores por domicílio rural, a taxa de envelhecimento, a existência de energia elétrica total rural, o índice de desenvolvimento da educação básica, o tipo de abastecimento de água no domicilio 
rural e o índice de desempenho do SUS e os indicadores agregados demográfico e ambiental.

Obteve-se significância estatística para o indicador ambiental, a existência de energia elétrica total rural, o tipo de abastecimento de água e para a tecnologia. Todos os efeitos das covariáveis, exceto tecnologia, são não concentradores de renda e se conformam com as hipóteses feitas, à exceção da variável ambiental. A tecnologia indica associação positiva significante com o índice de Gini, embora menos intensa que nas demais regiões.

\section{RESUMO E CONCLUSÕES}

Estudou-se a dispersão da renda no meio rural por meio da distribuição do índice de Gini municipal. Em termos médios, a dispersão de renda é alta (maior do que 75\%). Significativamente, a região Sul apresenta os menores níveis de dispersão. A tecnologia domina na região Centro-Oeste e não difere significativamente entre as regiões Sul e Sudeste. As condições de entorno também variam de região para região. Nota-se, contudo, uma tendência negativa para as regiões Norte e Nordeste, que apresentam valores mínimos em todos os atributos considerados, com exceção da taxa de envelhecimento e do desempenho no SUS. Na região Norte, os fatores existência de energia elétrica e o índice de desempenho do SUS demandam maior atenção. Na região Nordeste, o destino adequado do lixo, a educação básica e o abastecimento de água requerem atenção dos formuladores de políticas públicas. A energia elétrica e o desempenho no SUS demandam atenção também na região Centro-Oeste. Os índices agregados ambiental, sociais e demográficos têm os menores valores para as regiões Norte e Nordeste.

A medida de eficiência técnica DEA - proxy para tecnologia - destacou-se na explicação da variação da dispersão da renda bruta. Como ela é fortemente associada às imperfeições de mercado, estas também são responsáveis pela dispersão da renda bruta. Assim, o caminho das políticas públicas para eliminar as desigualdades nos campos passa pela remoção das imperfeições de mercado. E sem esta eliminação, a recémcriada Agência de Extensão Rural não terá condições de responder aos anseios da sociedade.

O modelo de reposta fracionária com o uso de GMM ajustou-se bem em todas as regiões, como medido pelo teste de especificação de Hansen. Dependendo da região, fez-se necessária a consideração de atributos agregados para a convergência dos estimadores (Sudeste e Centro-Oeste). É evidente das relações estimadas a influência positiva da tecnologia no nível de dispersão. Como esperado, a melhoria nas condições de entorno tende a reduzir a dispersão em todas as regiões.

\section{REFERÊNCIAS BIBLIOGRÁFICAS}

[1] Alves, E.; Souza, G.S. Pequenos estabelecimento em termos de área também enriquecem? Pedras e tropeços. Revista de Política Agrícola, 2015 (forthcoming).

[2] Alves, E.; Souza, G.S.; Rocha, D.P. Desigualdade nos campos sob a ótica do censo agropecuário 2006. Revista de Política Agrícola, v. 22, p. 67-75, 2013.

[3] Banker, R.D.; Charnes, A.; Cooper, W.W. Some models for estimating technical scale inefficiencies in Data Envelopment Analysis. Management Science, v. 30, n. 9, p. 1078-1092, 1984.

[4] Confederação Nacional da Agricultura. Índice de Desenvolvimento Rural CNA, 2013 (documento não publicado).

[5] Conover, M.J. Practical nonparametric statistics, 3rd ed., Wiley, New York, 1999.

[6] Cooper, W.W.; Seiford, L.M.; Zhu, J. Handbook on data envelopment analysis. 2nd ed. New York: Springer, 2011. 
[7] Davidson, R.; MacKinnon, J.G. Estimation and Inference in Econometrics. New York: Oxford University Press, 1993.

[8] Ferreira, C.R.; Souza, S.C.I. As aposentadorias e pensões e a concentração dos rendimentos domiciliares per capita no Brasil e na sua área rural: 1981 a 2003. Revista de Economia e Sociologia Rural, v. 45, n.4, p. 985-1011, 2007.

[9] Gallant, A.R. Nonlinear Statistical Models. New York: Wiley, 1987.

[10] Greene, W.H. Econometric Analysis. 7th edition. New Jersey: Prentice Hall, 2011.

[11] Helfand, S.M.; Rocha, R.; Vinhais, H.E.F. Pobreza e desigualdade de renda no Brasil rural: uma análise da queda recente. Pesquisa e Planejamento Econômico, v. 39, n. 1, p. 59-80, 2009.

[12] IBGE. Censo Agropecuário 2006. 2012a. Disponível em: http://www.ibge.gov.br/home/estatistica/economia/agropecuaria/censoagro/. Acesso em: 24 jan. 2012.

[13] IBGE. Censo Demográfico 2010. 2012b. Disponível em: http://censo2010.ibge.gov.br/. Acesso em: 24 jan. 2012.

[14] INEP. Nota Técnica do Índice de Desenvolvimento da Educação Básica. 2012. Disponível em: http://ideb.inep.gov.br/resultado/. Acesso em: 24 jan. 2012.

[15] Ministério da Saúde. IDSUS - Índice de Desempenho do SUS. Ano 1, 2011. Disponível em: http://portal.saude.gov.br/. Acesso em: 02 mar. 2012.

[16] Moreira, T.B.; Pinto, M.B.; Souza, G.S. Uma metodologia alternativa para mensuração de pressão sobre o mercado de câmbio. Estudos Econômicos, v. 34, p. 73-99, 2004.

[17] Neder, H.D.; Silva, J.L.M. Pobreza e distribuição de renda em áreas rurais: uma abordagem de inferência. Revista de Economia e Sociologia Rural, v. 42, n. 3, p. 469-486, 2004.

[18] Ney, M.G.; Hoffmann, R. A contribuição das atividades agrícolas e nãoagrícolas para a desigualdade de renda no Brasil rural. Economia Aplicada, v. 12, n. 3, p. 365-393, 2008.

[19] Ney, M.G.; Hoffmann, R. Educação, concentração fundiária e desigualdade de rendimentos no meio rural brasileiro. Revista de Economia e Sociologia Rural, v. 47, n. 1, p. 147-181, 2009.

[20] Papke, L.E.; Wooldridge, J.M. Econometric methods for fractional response variables with an application to 401(k) plan participation rates. Journal of Applied Econometrics, v. 11, p. 619-632, 1996.

[21] Ramalho, E.A.; Ramalho, J.J.S.; Henriques, P.D. Fractional regression models for second stage DEA efficiency analyses Journal of Productivity Analysis, v. 34, p. 239-255, 2010.

[22] Souza, G.S.; Gomes, E.G. Management of agricultural research centers in Brazil: A DEA application using a dynamic GMM approach. European Journal of Operational Research, v. 240, p. 819-824, 2015.

[23] Stata. Base Reference Manual. Stata Press, Texas, 2013.

[24] StataCorp. Longitudinal-Data/Panel-Data Reference Manual. College Station: Stata Press, 2012. 